\title{
Global Distribution of Surface Water Vapour Density Using in Situ and Reanalysis Data
}

\author{
Emmanuel Israel $^{1, ~ *, ~ A d e d a y o ~ K a y o d e ~ D a v i d ~}{ }^{1}$, Ojo Olusola Samuel ${ }^{1}$, Ashidi Ayodeji Gabriel ${ }^{1}$, \\ Emmanuel Grace Omolara ${ }^{2}$
}

${ }^{1}$ Department of Physics, Federal University of Technology, Akure, Nigeria

${ }^{2}$ Department of Computer, Federal University of Technology, Akure, Nigeria

Email address:

iemmanuel@futa.edu.ng (E. Israel),kdadedayo@futa.edu.ng(A. K. David), ojoso@futa.edu.ng (O. O. Samuel), agashidi@futa.edu.ng(A. A. Gabriel), larayet2017@gmail.com (E. G. Omolara)

${ }^{*}$ Corresponding author

\section{To cite this article:}

Emmanuel Israel, Adedayo Kayode David, Ojo Olusola Samuel, Ashidi Ayodeji Gabriel, Emmanuel Grace Omolara. Global Distribution of Surface Water Vapour Density Using in Situ and Reanalysis Data. Journal of Water Resources and Ocean Science.

Vol. 9, No. 3, 2020, pp. 64-70. doi: 10.11648/j.wros.20200903.12

Received: January 9, 2020; Accepted: January 21, 2020; Published: September 3, 2020

\begin{abstract}
Global spatial and annual distribution of surface water vapour density were estimated using 2005 -2016 monthly air temperature and relative humidity at $1^{\circ} \times 1^{\circ}$ resolution obtained from Era interim and NCEP/NCAR database products. Obtained results from reanalysis were statistically tested using in situ data from Tropospheric Data Acquisition Network (TRODAN) of The Center for Atmospheric Research (CAR). Four seasonal variations of surface water vapour density (winter (DJF), spring (MAM), summer (JJA) and autumn (SON)) was examined. Observed result from the two reanalysis follow similar trends with value from Era interim leading. High values ranges between $50 \mathrm{~g} / \mathrm{m}^{2}$ and $68 \mathrm{~g} / \mathrm{m}^{2}$ were observed in tropical regions and humid sub-tropical regions. Low values ranges between $8 \mathrm{~g} / \mathrm{m}^{2}$ and $38 \mathrm{~g} / \mathrm{m}^{2}$ were observed in Ice cap, Tundra and arid regions. High warming may be experienced in tropical and sub-tropical regions, similarly, climate change with alarming rate may be experienced in locations with low values. The annual cycle of surface water vapor density is clearly established from two reanalysis across world classified into twelve regions. The statistical test for the reanalysis present good result with a mean bias error, MBE, root mean square error, RMSE and R square of 20.56, 18.29, 0.87 and 5.87, 0.98, 0.93 for Era interim and NCEP/NCAR respectively.
\end{abstract}

Keywords: Global, Water Vapour, Reanalysis, Warming

\section{Introduction}

Water is the central of the hydrological cycle, which is inter or intra movement of water, in the Earth's atmosphere, oceans, and continents. Exchange of heat and energy between the earth's surface and the atmosphere and within the planet take place as a result of this process. The primary and most effective greenhouse gas in the atmosphere is water vapour, because it absorbs longwave radiation and radiates it back to the surface, which contributing to warming [1-5]. The atmosphere holds more water vapour as the temperature of the Earth's surface and atmosphere increases [1]. In the troposphere, water vapour molecules absorbed heat energy radiated from the Earth's surface. Likewise, the positive feedback, warming from increased greenhouse gases lead to an increase of water vapor and vice visa, is an item of climate models used for calculating the influence of increased greenhouse gases [6, 7]. Similarly, distribution and productivity of ecosystem depend on the dynamics of the water cycle [8]. As a result of climate change, hydrological and thermal regimes of rivers are expected to change and consequently affect freshwater ecosystems, water quality and human water use [9]. Many previous macro-scale hydrological modelling studies have been carried out to assess the impact of climate change on water availability at continental Changes in hydrology influence plant and animal species in various ways. Almost all land-dependent life, habitats and ecosystems depend on fresh water. Improved understanding of water vapour distribution and its interaction 
processes with clouds in conjunction with radiative impact, the atmospheric composition, solar radiation and volcanic eruption are highly required [10]. Atmospheric water vapor is characterized by various parameters, including vapor pressure, relative humidity, dew point temperature, water vapor density, and specific humidity.

Different data sources have been earlier used to investigate various water vapour forms across the world. [3, 11-13] used reanalysis data to study water vapour in different forms. In China, in situ measurement of atmospheric parameters such as surface air temperature, precipitation, surface humidity, surface winds, and radiation were compared with reanalysis data [14-17]. Comparison of precipitable water vapour from JRA-55, ERA-40, ERA-Interim, MERRA, NCEP/Department of Energy (DOE), and International Satellite Cloud Climatology Project with the analysis were carried out by $[10,18]$ used obtained data from NIMET to study the diurnal and seasonal variation of surface water vapour density across Nigeria. Alcamo et al., 2007, examined the long-term changes in global water resources, driven by socioeconomic and climatic changes. [19] examined the effect of climate change on hydrological regimes in Europe.

\section{Materials and Methods}

\subsection{Data Sources}

Global monthly temperature and relative humidity data for the period 2005-2016 were obtained from reanalysis NCEP/NCAR [20, 21] and Era interim [22] archive. In situ measurement data were obtained from the Tropospheric Data Acquisition Network (TRODAN) of the Center for Atmospheric Research (CAR). The Center for Atmospheric Research (CAR) is an activity Centre of the Nigerian National Space Research and Development Agency, NASRDA, committed to research and capacity building in the atmospheric and related sciences.

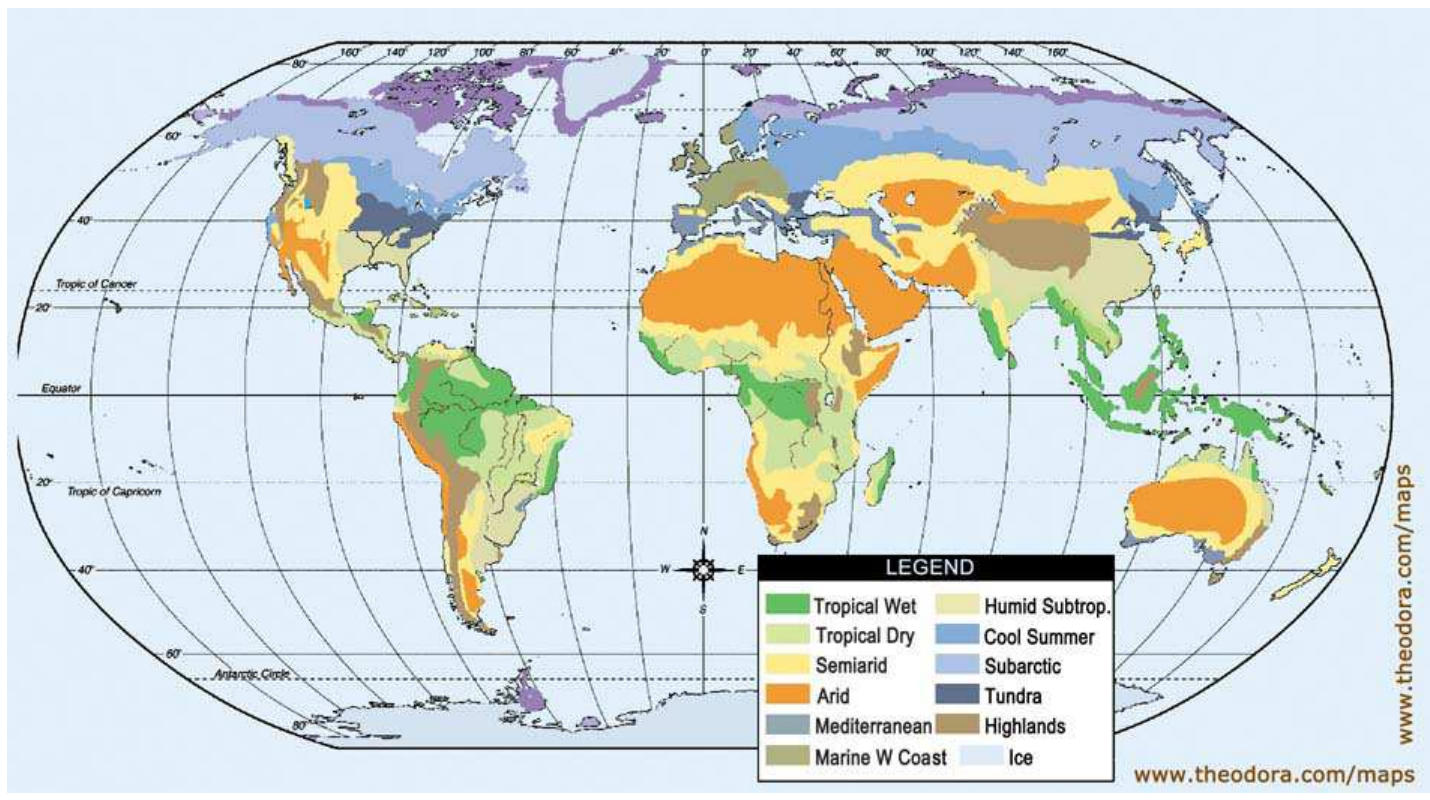

Figure 1. World Climatic Regions.

\subsection{Data Analysis}

Surface water vapour density (SWVD) in $\mathrm{g} / \mathrm{m}^{2}$ was calculated from the obtained temperature and relative humidity using [10]:

$$
S W V D=216.7\left\{\frac{e}{T}\right\}
$$

where e water vapour pressure in mbar, $\mathrm{T}$ is the temperature in kelvin. Water vapour pressure, e, was estimated from:

$$
e=R H\left\{\frac{e_{s}}{100}\right\}
$$

where $\mathrm{RH}$ is relative humidity $(\%), e_{s}$ is saturated water vapour pressure in mbar and is obtained from:

$$
e_{s}=6.1121 \exp \left\{\frac{17.502 t}{(t+240.97)}\right\}
$$

where $t$ is temperature in degree celcius.

Using the reanalysis data on the spatial resolution of $1^{\circ} \times$ $1^{\circ}$ grid, root-mean-square error (RMSE), mean bias error (MBE), R square, standard deviation, F statistic and $p$ value were determined to investigate the performance of each reanalysis product in relation to obtain in situ SWVD in the available location.

The RMSE measures the average magnitude of the error with a focus on extreme values.

$$
R M S E=\sqrt{\frac{1}{n} \sum_{i=1}^{n}\left(S W V D_{r i}-S W V D_{t i}\right)^{2}}
$$


where $S W V D_{r i}$ and $S W V D_{t i}$ represent surface water vapour density from reanalysis and TRODAN respectively.

Mean bias error (MBE) captures the average bias in the prediction and is calculated as:

$$
\frac{1}{n} \sum_{i=1}^{n}\left(S W V D_{r i}-S W V D_{t i}\right)
$$

Root mean square $\left(\mathrm{R}^{2}\right)$ tests the linear relation between two sources of data:

$$
R^{2}=\frac{\sum\left(S W V D_{r i}-\overline{S W V D_{r i}}\right)\left(S W V D_{t i}-\overline{S W V D_{t i}}\right)}{\sqrt{\sum\left(S W V D_{r i}-\overline{S W V D r i}\right)^{2}} \sqrt{\sum\left(S W V D_{t i}-\overline{S W V D_{t i}}\right)^{2}}}
$$

In these works, the world is grouped into different climatic regions as shown in Figure 1.

\section{Result and Discussion}

\subsection{Seasonal Spatial Distribution of Surface Water Vapour Density}

Global spatial distribution of surface water vapour density for winter, spring, summer and autumn which correspond to the months of December - January (DJF), March- May (MAM), June - August (JJA) and September November (SON) respectively obtained from Era interim and NCEP/NCAR are shown in Figures 2-3 respectively. Surface water vapour density obtained from Era interim oscillate between $16 \mathrm{~g} / \mathrm{m}^{2}$ and $68 \mathrm{~g} / \mathrm{m}^{2}$ across the four seasons. During winter (DJF), the highest values of surface water vapour density range between $54 \mathrm{~g} / \mathrm{m}^{2}$ and $67 \mathrm{~g} / \mathrm{m}^{2}$ were observed in part of Tropical wet dry region (central Africa and part of the coastal area of West Africa, North of Southern America with most part of Indonesia). Lower values of SWVD ranges between $25 \mathrm{~g} / \mathrm{m}^{2}$ and $33 \mathrm{~g} / \mathrm{m}^{2}$ were noticed in Icecap (Greenland), Tundra, and subarctic regions around Europe and Asia. Likewise, in spring highest value of SWVD were obtained in similar places like DJF with value ranges between $55 \mathrm{~g} / \mathrm{m}^{2}$ and $64 \mathrm{~g} / \mathrm{m}^{2}$, while the lowest value ranges between $38 \mathrm{~g} / \mathrm{m}^{2}$ and $42 \mathrm{~g} / \mathrm{m}^{2}$ in similar places like winter. During the summer period, JJA, SWVD values was higher in tropical wet of Indonesia, central Africa, and part of West Africa and Southern America with values ranges between $60 \mathrm{~g} / \mathrm{m}^{2}$ and $68 \mathrm{~g} / \mathrm{m}^{2}$. In most part of Europe, South Africa, and part of South America the values varies between $48 \mathrm{~g} / \mathrm{m}^{2}$ and $50 \mathrm{~g} / \mathrm{m}^{2}$. Minimum values of $36 \mathrm{~g} / \mathrm{m}^{2}-42 \mathrm{~g} / \mathrm{m}^{2}$ were noticed in the Ice cap, part of Namibia and Chile. Likewise, in the autumn season of SON, highest value ranges between $64 \mathrm{~g} / \mathrm{m}^{2}$ and $68 \mathrm{~g} / \mathrm{m}^{2}$ were observed in Indonesia, part of Brazil, Colombia, central Africa and part of West Africa. While the lowest values of $32 \mathrm{~g} / \mathrm{m}^{2}-34 \mathrm{~g} / \mathrm{m}^{2}$ were observed in the Ice cap, Tundra and Arid region of Southern Africa, Australia and Southern America.

However, NCEP/NCAR SWVD follow similar trends as that of Era interim though varies in values. In DJF, the values between $8 \mathrm{~g} / \mathrm{m}^{2}$ and $64 \mathrm{~g} / \mathrm{m}^{2}$. Highest values of 56 $\mathrm{g} / \mathrm{m}^{2}-64 \mathrm{~g} / \mathrm{m}^{2}$ were observed in Indonesia, central Africa, Brazil, Colombia and part of West Africa. Lowest values range between $10 \mathrm{~g} / \mathrm{m}^{2}$ and $20 \mathrm{~g} / \mathrm{m}^{2}$ were observed in Ice Cap, Australia, India and arid region of West Africa and North Africa. In Europe and Asia, the values vary between $12 \mathrm{~g} / \mathrm{m}^{2}$ and $46 \mathrm{~g} / \mathrm{m}^{2}$. In MAM, high value ranges between $88 \mathrm{~g} / \mathrm{m}^{2}$ and $68 \mathrm{~g} / \mathrm{m}^{2}$ were observed in similar places as that of winter, and lowest value ranges between $8 \mathrm{~g} / \mathrm{m}^{2}$ and 16 $\mathrm{g} / \mathrm{m}^{2}$ were observed in Arid region of West Africa and North Africa, minor part of Europe, North America and Ice Cap. In JJA period, highest values range $56 \mathrm{~g} / \mathrm{m}^{2}$ and 64 $\mathrm{g} / \mathrm{m}^{2}$ were obtained in similar places like spring. Minimum values of $4 \mathrm{~g} / \mathrm{m}^{2}$ and $18 \mathrm{~g} / \mathrm{m}^{2}$ were also noticed in similar places like winter. During autumn similar result were obtained. Since water vapour greatly contribute to more warming in the atmosphere, this will enhance the greenhouse effect which impedes climate change, especially where water vapour density is high. However, region with low water vapour density may be highly prone to climate changes. High values of water vapour density in tropical regions may be associated with the trapping radiant heat inside the atmosphere as a result of high temperature [23]. Low water vapour density in Ice cap can be attributed to ice albedo feedback, a situation which results to rising of temperatures as a result of decline of sea ice. Tundra and arid regions surface water vapou density may be anthropogenic activities which resulted in high rising in temperature [24]. In arid region, Australia it may be attributed to coral bleaching resulted from rising oceanic temperature [25].

\subsection{Spatial Temporal Anomaly of Surface Water Vapour Density from Era Interim and NCEP/NCAR}

Annual anomaly of SWVD obtained from Era interim and NCEP/NCAR for the period of 2005 -2016 were observed across the globe grouped into twelve climatic regions (Figure 4). The values of SWVD obtained from both NCEP/NCAR and Era interim depict a similar trend across all the regions with values of Era interim leading in all the regions except in the subarctic region. A sharp drop in the values of SWVD was observed in 2008 across the regions except in humid continental where an opposite result was observed. This may be attributed to heat waves experience during the year 2008 . The highest values of SWVD from Era interim range between $58 \mathrm{~g} / \mathrm{m}^{2}$ and $68 \mathrm{~g} / \mathrm{m}^{2}$ were observed in tropical wet, tropical wet and dry and humid sub-tropical regions. Similarly, from NCEP/NCAR, highest values oscillating between $58 \mathrm{~g} / \mathrm{m}^{2}$ and $62 \mathrm{~g} / \mathrm{m}^{2}$ were observed in Tropical wet and part of Tropical wet and dry regions. Lower values of 35 $\mathrm{g} / \mathrm{m}^{2}-38 \mathrm{~g} / \mathrm{m}^{2}$ and $8 \mathrm{~g} / \mathrm{m}^{2}-12 \mathrm{~g} / \mathrm{m}^{2}$ from Era interim and NCEP/NCAR were observed in ice cap and highland - arid regions respectively. High annual variation of SWVD was observed in the subarctic region for both Era interim and

NCEP/NCAR. This result implies that ice cap, Tundra, Arid regions may be most vulnerable to climate change. 

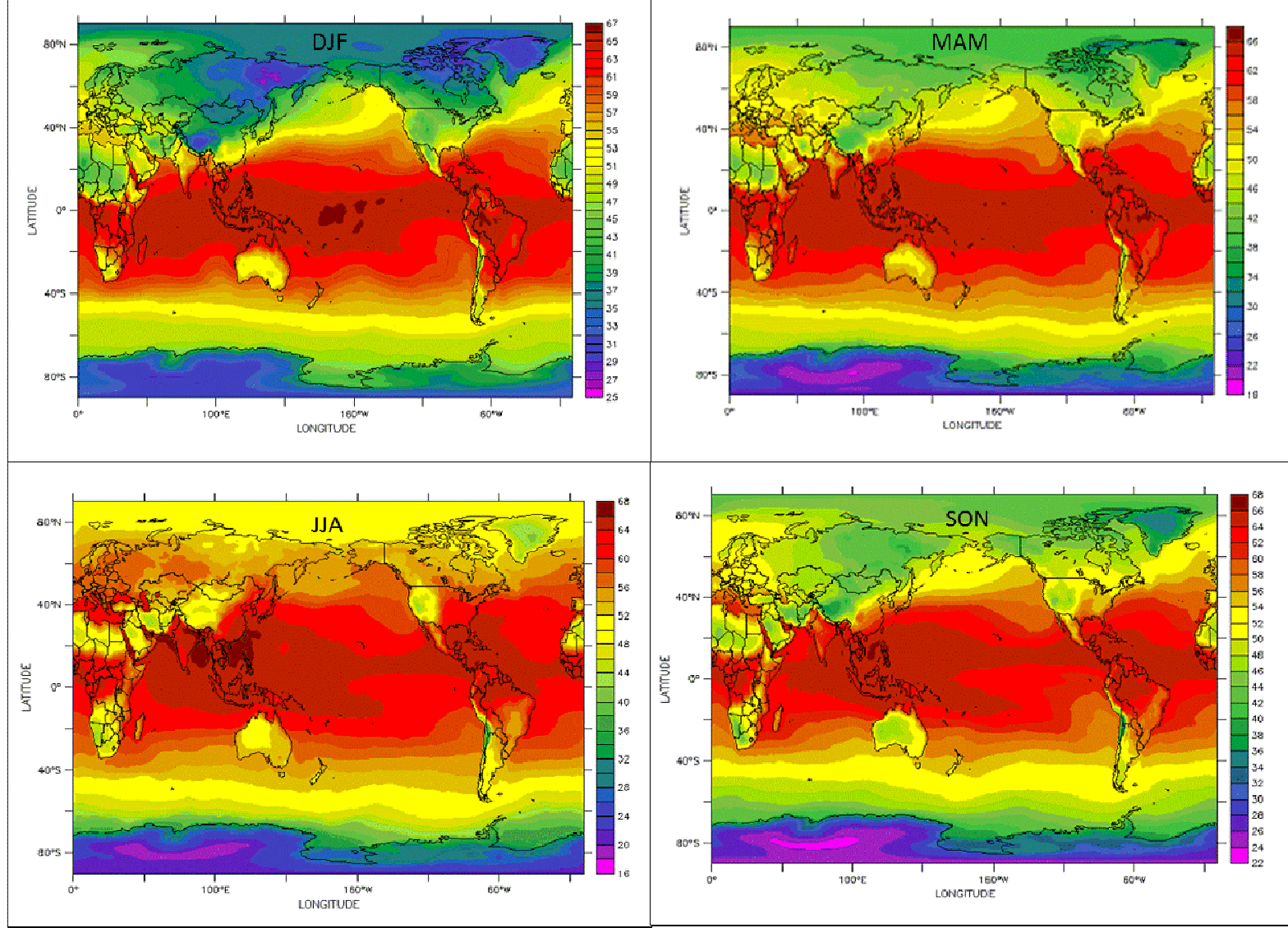

Figure 2. Global Seasonal-Spatial Distribution of Surface Water Vapour Density obtained from Era interim.

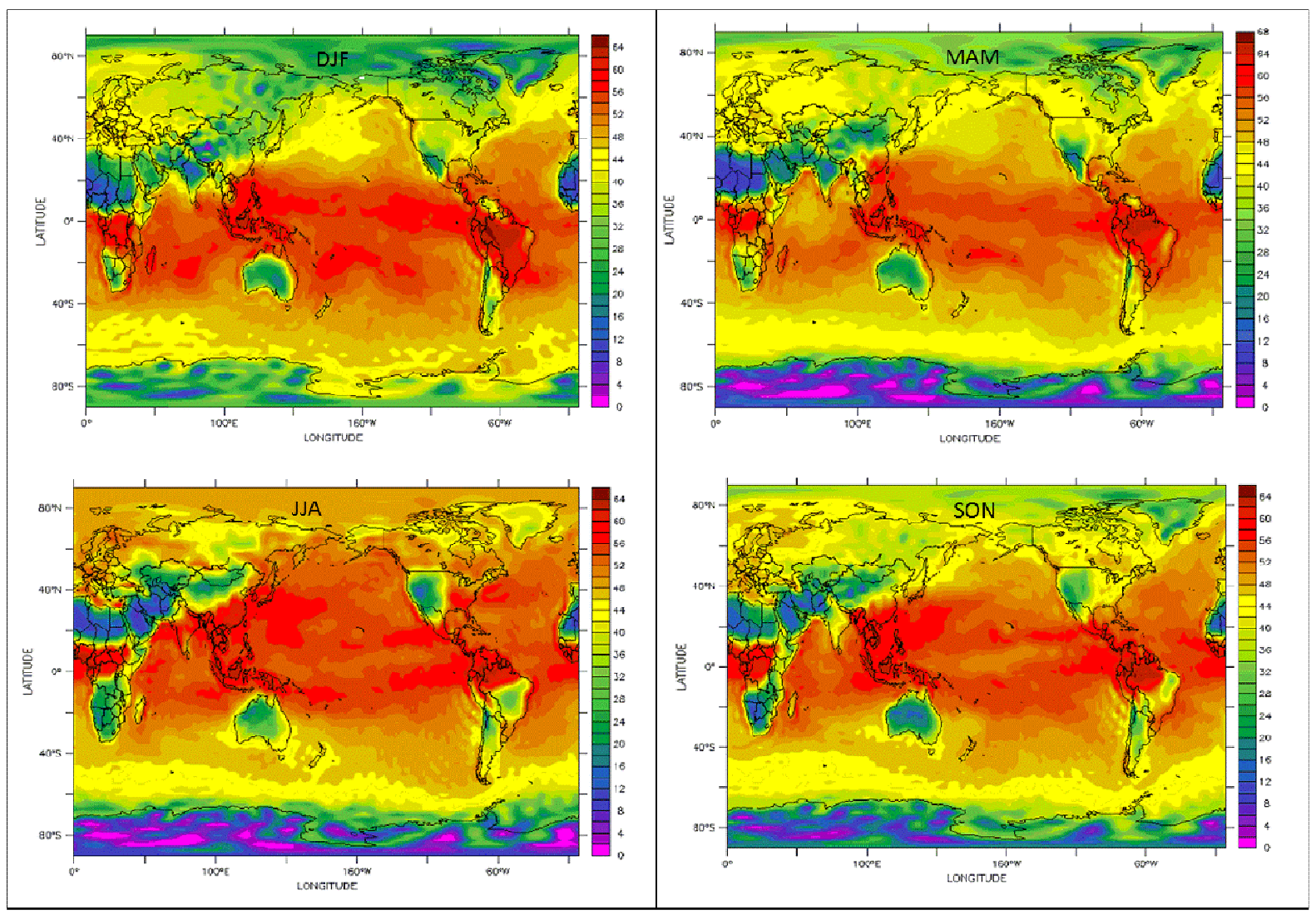

Figure 3. Global Seasonal-Spatial Distribution of Surface Water Vapour Density obtained from NCEP/NCAR. 


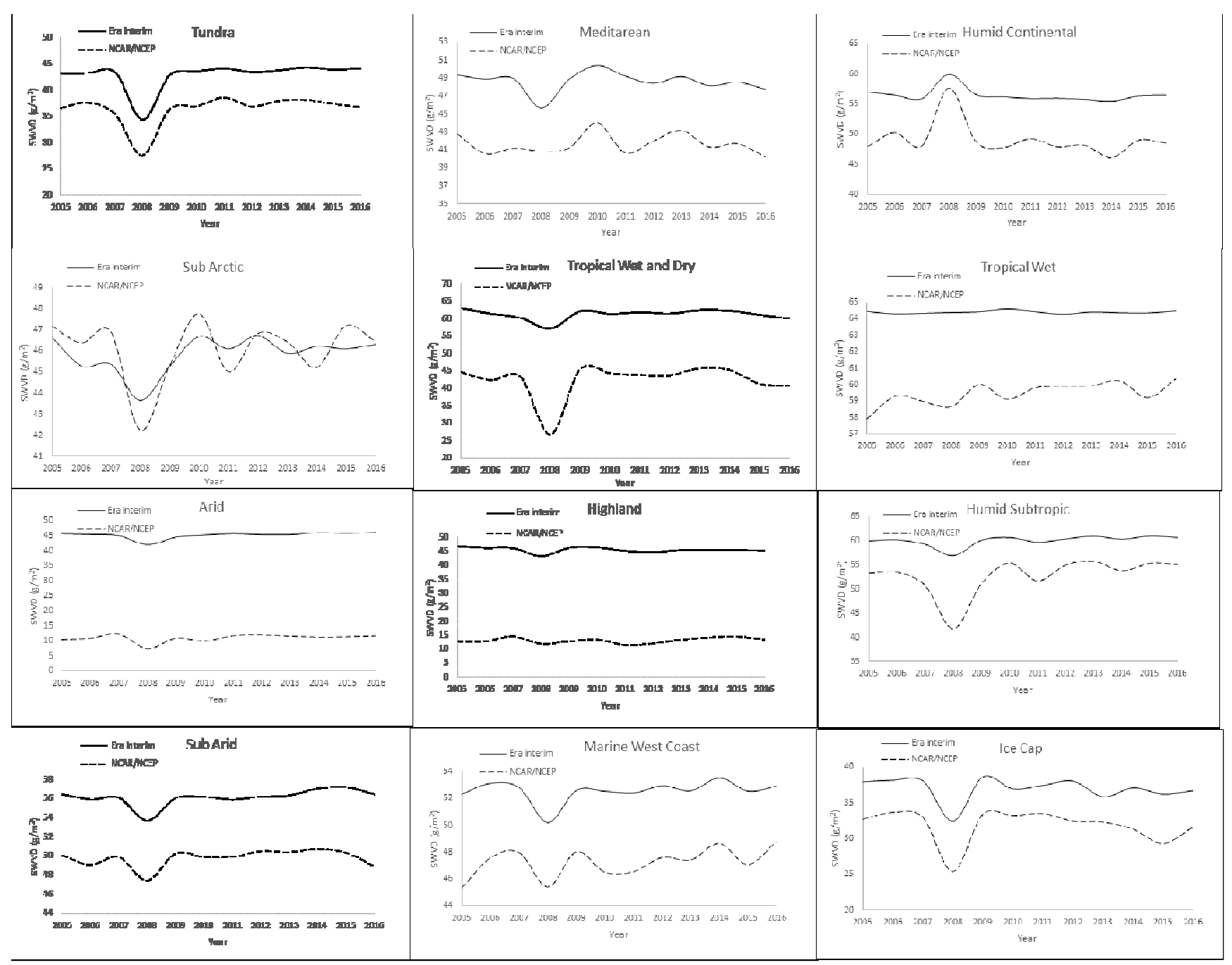

Figure 4. Annual Anomaly of Surface Water Vapour Density across the Global Region using Era interim and NCEP/NCAR.

\subsection{Comparison of Surface Water Vapour Density from Reanalysis and in Situ Measurement}

Monthly values of SWVD obtained from reanalysis data at $1.0^{\circ}$ grid were compared with in situ data obtained from the Tropospheric Data Acquisition Network (TRODAN) of The Center for Atmospheric Research (CAR). Of the two products, NCEP/NCAR produces the lowest bias, with MBE of 5.87 and a moderate RMSE of $0.98, \mathrm{R}^{2}$ of 0.93 (Table 1 ). The values of $F$ statistic, $p$ value and standard deviation established strong agreement between reanalysis and in situ data.

Table 1. Statistical Validation of Surface Water Density obtained from Era interim and NCEP/NCAR.

\begin{tabular}{lll}
\hline & Era interim & NCEP/NCAR \\
\hline RMSE & 18.29 & 0.98 \\
MBE & 20.56 & 5.87 \\
$\mathrm{R}^{2}$ & 0.87 & 0.93 \\
SD & 13.29 & 14.22 \\
F Statistic & 32.01 & 65.38 \\
p value & 0.00 & 0.00 \\
\hline
\end{tabular}

\section{Conclusion}

In this study, seasonal and internannual global variations and changes of surface water vapour density (SWVD) derived from two reanalysis products (i.e NCEP/NCAR, ERA-Interim) are evaluated against in situ data obtained from the Tropospheric Data Acquisition Network (TRODAN) of The Center for Atmospheric Research (CAR). The data from reanalysis were obtained at a spatial resolution of $1.0^{\circ} \times 1.0^{\circ}$ from 2005 to 2016. From the result obtained from Era interim, tropical wet, tropical wet dry and humid sub-tropical region experiences high values of surface water vapour density ranges between $60 \mathrm{~g} / \mathrm{m}^{2}$ and $68 \mathrm{~g} / \mathrm{m}^{2}$ with highest occurrence in winter and autumn. The lowest values range between $20 \mathrm{~g} / \mathrm{m}^{2}$ and $34 \mathrm{~g} / \mathrm{m}^{2}$ were established in Ice cap (Greenland), Tundra (Russia and Northern American) and arid regions of Australia, West and North Africa, Europe, Asia and Southern America). Likewise, NCEP/NCAR established high values in tropical wet and part of Tropical wet and dry. However, low values obtained from NCEP/NCAR were more prominent in arid region than Ice cap and Tundra regions. The observed low values may be attributed to various factors such as rising in 
oceanic temperature, anthropogenic factors and so on. Annual distribution across the regions showed that the values of SWVD obtained from Era interim lead in all the regions except the subarctic region where SWVD oscillate. In both Era interim and NCEP/NCAR discernible low value was noticed in the year 2008 across the regions, except in humid continental regions where high percentages of surface water vapour density were noticed. High values of water vapour may cause solar radiation to reach the Earth's surface and cause the surface of the planet to be more heated. Global warming, which is the result of an increase in magnitude of the greenhouse effect, caused by the presence of water vapour and other greenhouse gases. Whereas regions with low surface water vapour density experienced high global warming. Statistical test established good relation between reanalysis and in situ data through mean bias error and root mean square error.

\section{Acknowledgements}

We would like to acknowledge The Tropospheric Data Acquisition Network (TRODAN).

\section{References}

[1] Held, I. M., Soden, B. J.(2000). Water vapor feedback and global warming. Annu. Rev. energy Environ. 25, 441-475.

[2] Zhao, L., Lee, X., Liu, S. (2013). Correcting surface solar radiation of two data assimilation systems against FLUXNET observations in North America. J. Geophys. Res. Atmos. 118, 9552-9564.

[3] Dai, A., Wang, J., Ware, R. H., Van Hove, T.(2002). Diurnal variation in water vapor over North America and its implications for sampling errors in radiosonde humidity. J. Geophys. Res. Atmos. 107, ACL-11.

[4] Khalameyda, D. D. (2011). Influence of fluctuations in the troposphere refractive index on the interferometer measurement accuracy of radio wave angles of arrival. Telecommun. Radio Eng. 70.

[5] Khaniani, A. S., Nikraftar, Z., Zakeri, S. (2020). Evaluation of MODIS Near-IR water vapor product over Iran using groundbased GPS measurements. Atmos. Res. 231, 104657.

[6] Zhao, Y., Gong, L., Zhou, B., Huang, Y., Liu, C. (2016). Detecting tomatoes in greenhouse scenes by combining AdaBoost classifier and colour analysis. Biosyst. Eng. 148, 127-137.

[7] Vaquero-Martínez, J., Antón, M., de Galisteo, J. P. O., Román, R., Cachorro, V. E. (2018). Water vapor radiative effects on short-wave radiation in Spain. Atmos. Res. 205, 18-25.

[8] Dadson, S., Acreman, M., Harding, R. (2013). Water security, global change and land--atmosphere feedbacks. Philos. Trans. R. Soc. A Math. Phys. Eng. Sci. 371, 20120412.

[9] van Vliet, M. T. H., Franssen, W. H. P., Yearsley, J. R., Ludwig, F., Haddeland, I., Lettenmaier, D. P., Kabat, P. (2013). Global river discharge and water temperature under climate change. Glob. Environ. Chang. 23, 450-464.
[10] Adeyemi, B., Ogolo, E. O. (2014). Diurnal and seasonal variations of surface water vapour density over some meteorological stations in Nigeria. Ife J. Sci. 16, 181-189.

[11] Wang, J., Zhang, L., Dai, A. (2005). Global estimates of water-vapor-weighted mean temperature of the atmosphere for GPS applications. J. Geophys. Res. Atmos. 110.

[12] Dessler, A. E., Davis, S. M. (2010). Trends in tropospheric humidity from reanalysis systems. J. Geophys. Res. Atmos. 115 .

[13] Serreze, M. C., Barrett, A. P., Stroeve, J. (2012). Recent changes in tropospheric water vapor over the Arctic as assessed from radiosondes and atmospheric reanalyses. J. Geophys. Res. Atmos. 117.

[14] Shi, Q., Liang, S. (2013). Characterizing the surface radiation budget over the Tibetan Plateau with ground-measured, reanalysis, and remote sensing data sets: 1 . Methodology. J. Geophys. Res. Atmos. 118, 9642-9657.

[15] Wang, K., Ma, Q., Li, Z., Wang, J. (2015). Decadal variability of surface incident solar radiation over China: Observations, satellite retrievals, and reanalyses. J. Geophys. Res. Atmos. $120,6500-6514$.

[16] Ebita, A., Kobayashi, S., Ota, Y., Moriya, M., Kumabe, R., Onogi, K., Harada, Y., Yasui, S., Miyaoka, K., Takahashi, K. (2011). The Japanese 55-year reanalysis 'JRA-55': an interim report. Sola. 7, 149-152.

[17] Jia, B., Xie, Z., Dai, A., Shi, C., Chen, F. (2013). Evaluation of satellite and reanalysis products of downward surface solar radiation over East Asia: Spatial and seasonal variations. J. Geophys. Res. Atmos. 118, 3431-3446.

[18] Gil-Alana, L. A. (2005). Statistical modeling of the temperatures in the Northern Hemisphere using fractional integration techniques. J. Clim. 18, 5357-5369.

[19] Arnell, N. W. (1999). The effect of climate change on hydrological regimes in Europe: a continental perspective. Glob. Environ. Chang. 9, 5-23.

[20] Kalnay, E., Kanamitsu, M., Kistler, R., Collins, W., Deaven, D., Gandin, L., Iredell, M., Saha, S., White, G., Woollen, J. (1996). The NCEP/NCAR 40-year reanalysis project. Bull. Am. Meteorol. Soc. 77, 437-472.

[21] Kistler, R., Kalnay, E., Collins, W., Saha, S., White, G., Woollen, J., Chelliah, M., Ebisuzaki, W., Kanamitsu, M., Kousky, V. (2001) The NCEP--NCAR 50-year reanalysis: monthly means CD-ROM and documentation. Bull. Am. Meteorol. Soc. 82, 247-268.

[22] Dee, D. P., Uppala, S. M., Simmons, A. J., Berrisford, P., Poli, P., Kobayashi, S., Andrae, U., Balmaseda, M. A., Balsamo, G., Bauer, d P. (2011) The ERA-Interim reanalysis: Configuration and performance of the data assimilation system. Q. J. R. Meteorol. Soc. 137, 553-597.

[23] Seidel, D. J., Fu, Q., Randel, W. J., Reichler, T. J. (2008). Widening of the tropical belt in a changing climate. Nat. Geosci. 1, 21.

[24] Blok, D., Heijmans, M., Schaepman-Strub, G., van Ruijven, J., Parmentier, F. J. W., Maximov, T. C., Berendse, F. (2011). The cooling capacity of mosses: controls on water and energy fluxes in a Siberian tundra site. Ecosystems. 14, 1055-1065 (2011). 
[25] Wooldridge, S. A. (2009). Water quality and coral bleaching thresholds: Formalising the linkage for the inshore reefs of the Great Barrier Reef, Australia. Mar. Pollut. Bull. 58, 745-751. 